\title{
Curcumin decreases astrocytic reaction after gliotoxic injury in the rat brainstem
}

\author{
Curcumina reduz a reação astrocitária após injúria gliotóxica no tronco encefálico de ratos
}

\author{
Eduardo Bondan ${ }^{1,2}$, Carolina Cardoso', Maria de Fátima Martins ${ }^{1,2}$
}

\begin{abstract}
Recent studies have demonstrated that curcumin (Cur) has antioxidant, anti-inflammatory and anti-fibrotic effects. Ethidium bromide (EB) injections into the central nervous system (CNS) are known to induce local oligodendroglial and astrocytic loss, resulting in primary demyelination and neuroinflammation. Peripheral astrogliosis is seen around the injury site with increased immunoreactivity to glial fibrillary acidic protein (GFAP). This investigation aimed to evaluate the effect of Cur administration on astrocytic response following gliotoxic injury. Wistar rats were injected with EB into the cisterna pontis and treated, or not, with Cur (100 mg/kg/day, intraperitoneal route) during the experimental period. Brainstem sections were collected at 15, 21 and 31 days after EB injection and processed for GFAP immunohistochemical staining. Astrocytic reactivity was measured in a computerized system for image analysis. In Cur-treated rats, the GFAP-stained area around the lesion was significantly smaller in all periods after EB injection compared to untreated animals, showing that Cur reduces glial scar development following injury.
\end{abstract}

Keywords: astrocytes; curcumin; ethidium; gliosis; gliotoxin.

\section{RESUMO}

Estudos recentes têm demonstrado que a curcumina (Cur) possui efeitos antioxidantes, anti-inflamatórios e antifibróticos. Sabe-se que a injeção de brometo de etídio (EB) no sistema nervoso central induz a perda oligodendroglial e astrocitária, resultando em desmielinização primária e neuroinflamação. Astrogliose periférica é observada ao redor da lesão com aumento da imunorreatividade à proteína glial fibrilar ácida (GFAP). A presente investigação objetivou avaliar o efeito da Cur sobre a resposta astrocitária após injúria gliotóxica. Ratos Wistar foram injetados com EB na cisterna basal e tratados ou não com Cur (100 mg/kg/dia, via intraperitoneal) durante o período experimental. Amostras do tronco encefálico foram coletadas aos 15, 21 e 31 dias pós-injeção de EB e processadas para estudo imuno-histoquímico para a GFAP.A reatividade astrocitária foi medida em um sistema computadorizado para análise de imagem. Nos ratos tratados com Cur, a área marcada para GFAP foi significantemente menor em todos os períodos pós-injeção de EB, indicando que a Cur reduz o desenvolvimento da cicatriz glial após injúria.

Palavras-chave: astrócitos; curcumina; etídio; gliose; gliotoxina.

Ethidium bromide (EB) injections in the white matter of the central nervous system (CNS) are known to act like a gliotoxin, causing local oligodendroglial and astrocytic death, leading to primary demyelination, neuroinflammation, blood-brain barrier disruption and Schwann cell invasion due to the glia limitans breakdown ${ }^{1,2,3,4}$. Surviving astrocytes present a vigorous reaction around the injury site with increased immunoreactivity to the specific cell marker glial fibrillary acidic protein (GFAP), as well as re-expression of vimentin ${ }^{3}$.

Curcumin (Cur) [diferuloylmethane or 1,7-bis-(4-hydroxy3-methoxyphenyl)-1,6-heptadiene-3,5-dione] is the major yellow-orange pigment of turmeric, a common spice and coloring agent derived from the rhizome of the East Indian plant Curcuma longa, with a long history in Asian traditional cooking and medicine ${ }^{5,6,7}$. Recently, Cur has been shown to exhibit proven therapeutic benefits (including antioxidant, anti-inflammatory, anti-cancer and anti-fibrotic effects) in many pathological conditions, such as Alzheimer's disease, Parkinson's disease, multiple sclerosis, epilepsy, cerebral injury, cancer, allergy, asthma, bronchitis, colitis, rheumatoid arthritis, renal ischemia, psoriasis, scleroderma, diabetes, obesity, depression, fatigue and acquired immunodeficiency disease ${ }^{6,7,8}$.

Specifically regarding the CNS, Cur was capable of providing neuroprotection after spinal cord injury, inhibiting apoptosis and neuron loss and attenuating oxidative stress in astrocytes and reactive astrogliosis , $^{90,11,12,13}$, suggesting that

\footnotetext{
'Universidade Paulista, Patologia Ambiental e Experimental, São Paulo SP, Brasil;

${ }^{2}$ Universidade Cruzeiro do Sul, Medicina Veterinária, São Paulo SP, Brasil.

Correspondence: Eduardo Bondan; Patologia Ambiental e Experimental, Universidade Paulista; Rua Caconde, 125 / 51; $01425-011$ São Paulo SP, Brasil; E-mail: bondan@uol.com.br

Conflict of interest: There is no conflict of interest to declare.
}

Received 21 December 2016; Received in final form 15 April 2017; Accepted 04 May 2017. 
Cur might beneficially affect astrocyte population in the CNS inflammatory environment by regulating both NF- $\kappa \beta$ and SOX9 signaling pathways ${ }^{14,15}$.

In this context, the aim of this study was to evaluate whether Cur had the capacity to affect astrocyte response during the process of demyelination and remyelination following gliotoxic injury induced by ethidium bromide (EB).

\section{METHODS}

The animal procedures were performed in accordance with the guidelines of the Committee on Care and Use of Laboratory Animal Resources and the Brazilian Institutional Ethics Committee, Universidade Paulista (protocol number 235/14, CEUA/ICS/UNIP). Forty-eight adult (4-5-month-old) male Wistar rats were subjected to a local injection of 10 microlitres of $0.1 \% \mathrm{~EB}$ into the cisterna pontis, an enlarged subarachnoid space below the ventral surface of the pons. All rats were anesthetized with $2.5 \%$ thiopental $(50 \mathrm{mg} / \mathrm{ml})$ by intraperitoneal (IP) route and a burr-hole was made on the right side of the skull, $8 \mathrm{~mm}$ behind the fronto-parietal suture. Injections were given freehand, using a Hamilton syringe fitted with a $35^{\circ}$ angled polished 26-gauge needle, into the cisterna pontis. Rats were then distributed into two groups - control rats (group I, $\mathrm{n}=24$ ) and rats treated with $100 \mathrm{mg} / \mathrm{kg} / \mathrm{day}$ of Cur (Sigma Aldrich, St. Louis, MO, USA, C1386; 100 mg of Cur was dissolved in $1.0 \mathrm{~mL}$ dimethyl sulfoxide and $0.5 \mathrm{~mL} 0.9 \%$ saline solution) by IP route (group II, $\mathrm{n}=24$ ). Group I received an equal volume of dimethyl sulfoxide by IP route. The first injection was done immediately after surgery and then injections were performed once every 24 hours for the experimental period. The animals were kept under controlled light conditions (12 hours light-dark cycle) and water and food were given ad libitum during the experimental period.

For the immunohistochemical study of the expression of the astrocytic marker GFAP, six rats per group were anesthetized and subjected to intracardiac perfusion with buffered $10 \%$ formaldehyde solution at each of the following periods $-15,21$ and 31 days post-injection. Their brains were then removed and kept for three days in the same fixative. After a 72 hour period, the brainstem was removed through two coronal cuts, beginning at the cerebral peduncles of the mesencephalon and ending in the posterior part of the pons. A rostrocaudal sequence of coronal sections from the brainstem was done and $5 \mu \mathrm{m}$ sections were mounted on silanized slides and subjected to GFAP immunostaining using the avidin-biotin peroxidase complex method. Briefly, the sections were dewaxed in xylene and rehydrated in a crescent graded series of ethanol solutions. Antigen retrieval was done by transferring the slides to a $10 \mathrm{mM}$ sodium citrate buffer (pH 6.0) at $95^{\circ} \mathrm{C}$ for 20 minutes. Endogenous peroxidase was blocked by $3 \%$ hydrogen peroxide for 10 minutes at room temperature. Two washes with Tris/HCl buffer $\mathrm{pH} 6.0$ (Wash buffer 10x, S3006, Dako, Glostrup, Danmark) were done between incubations. Polyclonal rabbit anti-GFAP immunoglobulin (Z0334, Dako), at a dilution of 1:1000, was used as the primary antibody for 16 hours, followed by the application of biotinylated secondary antibody (Dako Universal LSAB ${ }^{\mathrm{TM}}$ 2 System - HRP, K0690), according to the manufacturer's instructions. Immunoreactivity was visualized by incubating the sections in a solution containing $0.1 \%$ diaminobenzidine (DAB, K3467, Dako). Sections were then counterstained by Harris' modified hematoxylin solution, dehydrated and mounted in Entellan (Merck, Germany).

Ten photomicrographs per section, of each animal, were taken from randomly-chosen microscopic fields of the periphery of the lesion site using a Nikon E200 microscope (Kanagawa, Japan; 10x objective) equipped with a Nikon Coolpix digital camera linked to a liquid crystal display monitor. Astrocytic evaluation was done in the brainstem of animals from both groups using a computerized image analysis system (Image-Pro-Plus 4.5, Media Cybernetics, Silver Spring, USA), measuring by colorimetry the area stained brown (data are expressed in pixels). Negative controls for immunostaining (sections lacking primary antibody application) were performed. Data were analyzed by two-way ANOVA followed by Bonferroni's test, and statistical significance was set at $\mathrm{p}<0.05$.

\section{RESULTS}

The EB-induced lesions found in this study were similar to those previously described in other investigations using this gliotoxin in the rat brainstem ${ }^{1,23,16}$. These lesions exhibited extensive demyelination in the ventral surface of the brainstem and showed phagocytic cells, myelin debris and naked axons in their core. At peripheral locations, oligodendrocytes and Schwann cells were noted, the latter occurring in areas of enlarged extracellular spaces devoid of astrocytic processes. Astrocyte extensions were observed near the incipient oligodendroglial remyelination at the periphery, and Schwann cells also appeared to contribute to myelin repair. Some lymphocytes and infiltrating pial cells were occasionally seen, the first contacting phagocytic cells and myelin debris.

Figure 1 shows the injection site for the gliotoxin. It was observed that the EB-induced lesions from group II (Curtreated rats) showed a decreased GFAP expression close to the edges of the injury site. Astrocytes presented fewer and thinner GFAP-stained processes at the periphery of the injury site in all periods (Figure 2) and no astrocytes were observed in the central areas of the lesions, even at 31 days after the EB injection.

Table and Figure 3 show the mean areas with GFAP staining in pixels from both groups at all analyzed periods (15, 21 and 31 days). The two-way ANOVA showed that both treatment (F1,42 $=393,01, \mathrm{p}<0.0001)$, and days of observation $(\mathrm{F} 2,42=15.91, \mathrm{p}$ $<0.0001$ ), affected the results and no interaction was observed between these two factors $(\mathrm{F} 2,42=0,79, \mathrm{p}=0.45)$. The Bonferronis 


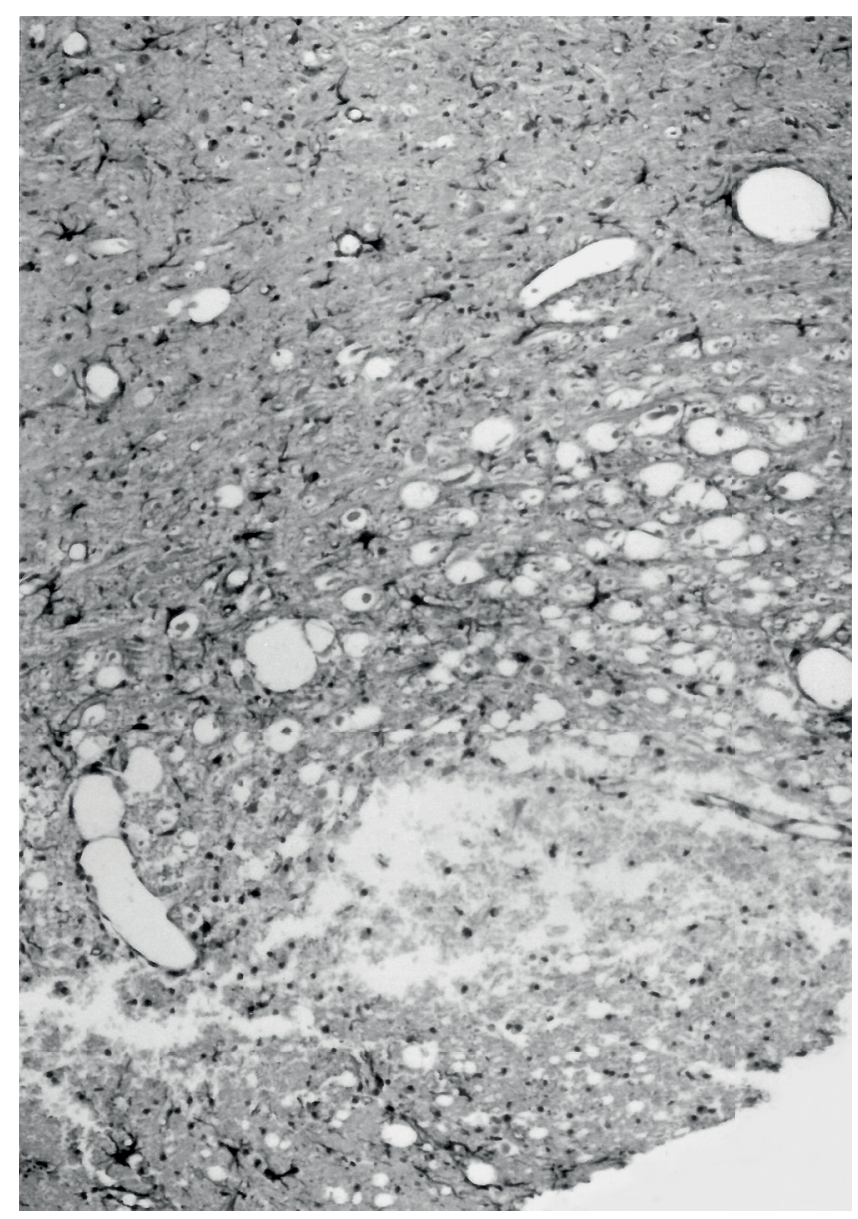

GFAP: glial fibrillary acidic protein

Figure 1. Ethidium bromide injection site. Note the central disappearance of GFAP-positive cells at 15 days following gliotoxin. GFAP immunohistochemistry. Objective 10x.

test indicated a decreased GFAP expression in the Cur-treated group in relation to the untreated one in all days of observations. At 15 days, the mean brown-stained area was significantly smaller in rats treated with Cur (group II - 40,976 $\pm 2,454$ pixels) compared to untreated rats (group I - 68,479 $\pm 5,487$ pixels). Similar findings were seen at 21 days $(46,049 \pm 5,463$ pixels in group II versus 69,689 $\pm 5,212$ pixels in group I) and 31 days (mean areas of 50,338 \pm 2,625 pixels and 76,920 \pm 4,79 pixels, respectively, in groups II and I).

\section{DISCUSSION}

Astrocytes are among the most structurally complex cells in the CNS, and their activation appears in a wide spectrum of CNS injuries and diseases ${ }^{17}$. Several genes are implicated in morphological alterations of astrocytes. Glial fibrillary acidic protein, an intermediate filament-III protein highly expressed in white matter astrocytes and a subset of gray matter astrocytes, is thought to modulate astrocyte motility and shape, providing structural stability to processes, maintaining their mechanical strength and supporting neighboring neurons, myelinating oligodendrocytes and the blood-brain barrier ${ }^{17,18,19}$. Astroglial cells respond to CNS injury and other neuro-disturbing conditions by undergoing "reactive astrogliosis", a process whereby astrocytes undergo cellular hypertrophy and proliferation ${ }^{19,20,21,22,23,24}$. Increased GFAP is a hallmark of reactive astrocytes and this cytoskeletal protein contributes to the barrier effect produced by the glial scar that mitigates axonal extension and CNS repair 9

Astrocyte precursors and immature astrocytes present principally nestin and vimentin and, during development as astrocytes mature, nestin expression disappears, GFAP becomes increasingly expressed and vimentin decreases to undetectable levels ${ }^{21}$. During astrogliosis, astrocytes re-express vimentin and nestin ${ }^{21}$. In the EB demyelinating model, re-expression of vimentin and strong astrocytic immunoreactivity to GFAP were described in the rat brainstem from the $3^{\text {rd }}$ to the $31^{\text {st }}$ day following gliotoxic injection ${ }^{3}$. This increased GFAP expression around the EB-induced lesions was confirmed in the present study.

Activated astrocytes release a variety of factors that participate in neuroinflammation, possibly aggravating initial injury. The NF- $\kappa \beta$ signaling pathway is very important for the effects of pro-inflammatory cytokines TNF- $\alpha$ and IL-1 $\beta^{15}$, which represent important factors in the initial activation of astrocytes and are produced in great numbers in brainstem lesions induced by $\mathrm{EB}^{25}$. Under the influence of many relevant factors, astrocytes will lead to dense glial scar formation and will produce large amounts of extracellular matrix components, such as chondroitin sulfate proteoglycan, changing the axonal growth environment and severely inhibiting nerve regeneration ${ }^{15}$.

Yuan et al. ${ }^{15}$ observed that Cur suppressed the NF- $\kappa \beta$ signaling pathway, down-regulating the expression of chemokines MCP-1, RANTES and CXCL10 released by astrocytes and decreasing macrophage and T-cell infiltration, thus reducing inflammation in the glial scar environment in an experimental model of spinal cord injury. Additionally, by silencing the transcription factor SOX9, Cur reduced the deposition of extracellular matrix chondroitin sulfate proteoglycan, contributing to recovery of neurological function. Therefore, these authors stated that Cur could both inhibit the formation of intracellular (i.e., GFAP) and extracellular (i.e., chondroitin sulfate proteoglycan) glial scar components and promote neurological recovery after injury.

Any injury to the CNS (caused by trauma, hypoxia, toxin or an infectious agent) represents a complex system of interacting cell types that react in a stereotyped way, forming a mature lesion with two distinct components - the periphery with hypertrophic astrocytes, whereas the lesion core is composed of NG2 glia/oligodendrocyte precursor cells, meningeal- and/or vascular-derived fibroblasts, pericytes, ependymal cells and phagocytic macrophages ${ }^{24}$.

Both oligodendrocyte and astrocyte losses are key events within the EB-induced lesion, while axons remain unaffected. 
EB
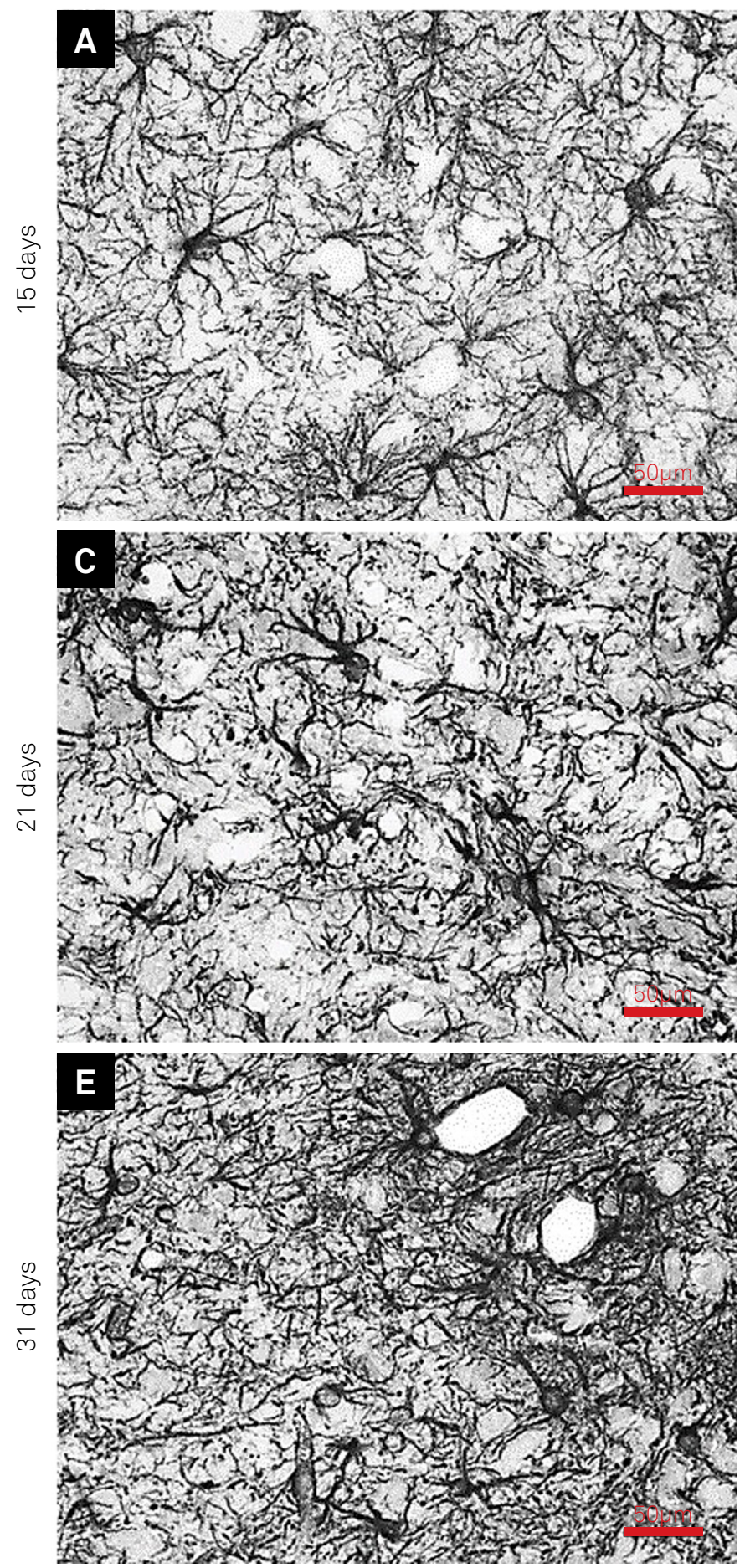

$E B+C u r$
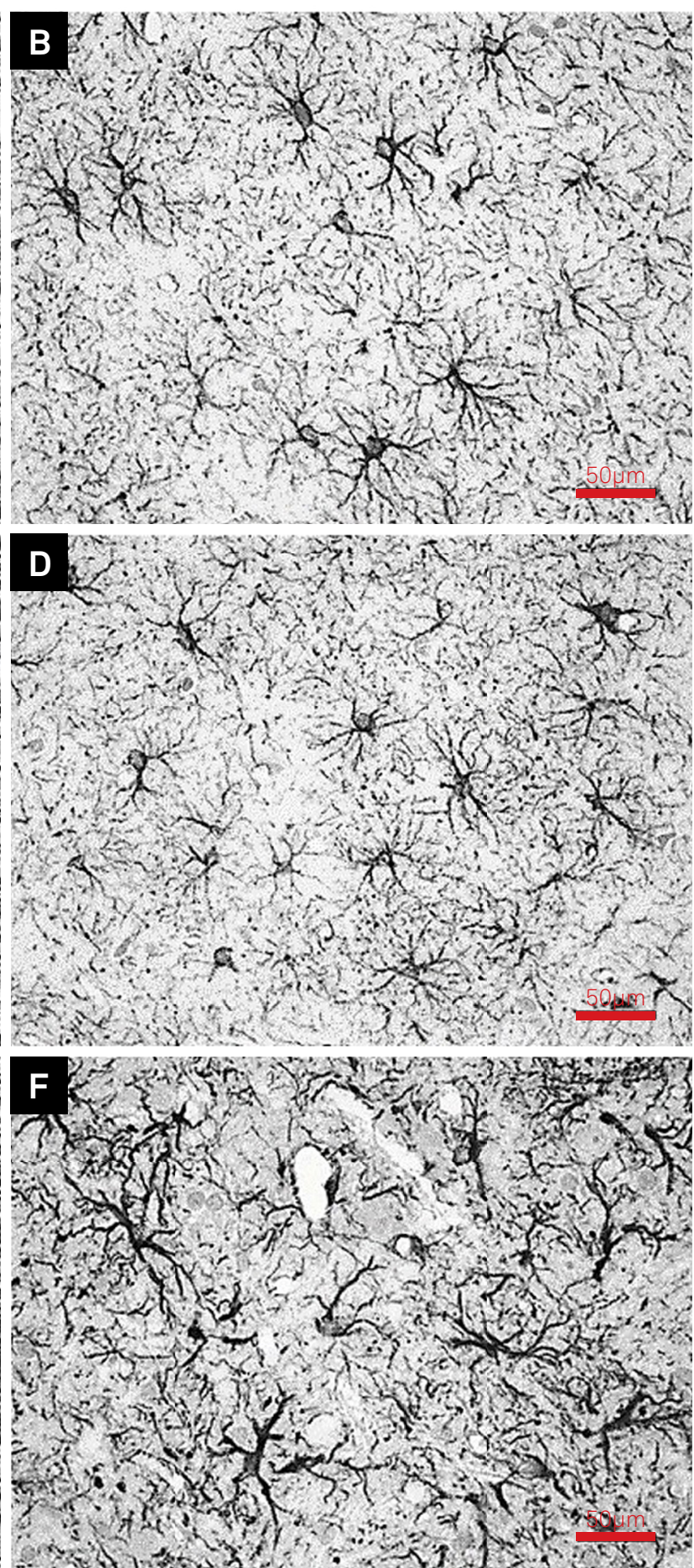

Figure 2

The mechanism of selective glial death supposedly occurs through EB's action as a minor-groove DNA intercalator. Other evidences suggest that although EB does intercalate both chromosomal and mitochondrial DNA, it only affects mtDNA transcription ${ }^{26}$. So, an injection of EB into the white matter is likely to affect mtDNA in all cells of the lesion site, although neurons and endothelial cells appear to be less sensitive than glia in rodent models ${ }^{4}$.

Astrocyte disappearance due to the gliotoxic effect and direct mechanical damage due to intracisternal injection are identified as factors capable of disturbing the blood-brain barrier, thus allowing monocyte and lymphocyte infiltration. 
Table. Areas in pixels with GFAP staining in rats injected with EB, treated (group II) or not (group I) with Cur.

\begin{tabular}{|c|c|c|c|c|c|c|}
\hline \multirow{2}{*}{ Animal } & \multicolumn{3}{|c|}{ Group I - EB injection } & \multicolumn{3}{|c|}{ Group II - EB injection + Cur } \\
\hline & 15 days $\left(\mu m^{2}\right)$ & 21 days $\left(\mu \mathrm{m}^{2}\right)$ & 31 days $\left(\mu m^{2}\right)$ & 15 days $\left(\mu m^{2}\right)$ & 21 days $\left(\mu m^{2}\right)$ & 31 days $\left(\mu m^{2}\right)$ \\
\hline 1 & 65,934 & 62,477 & 77,902 & 40,763 & 48,372 & 47,883 \\
\hline 2 & 67,273 & 67,376 & 74,873 & 39,478 & 46,803 & 50,631 \\
\hline 3 & 65,206 & 65,802 & 69,81 & 37,392 & 39,983 & 51,705 \\
\hline 4 & 63,882 & 80,163 & 79,653 & 43,89 & 50,382 & 47,332 \\
\hline 5 & 61,371 & 71,885 & 84,926 & 41,238 & 55,223 & 49,77 \\
\hline 6 & 74,982 & 70,727 & 73,714 & 40,943 & 38,674 & 55,368 \\
\hline 7 & 73,282 & 68,526 & 73,863 & 39,207 & 45,87 & 51,646 \\
\hline 8 & 75,903 & 70,557 & 80,623 & 44,893 & 43,087 & 48,372 \\
\hline Mean & 68,479 & 69,689 & 76,92 & 40,976 & 46,049 & 50,338 \\
\hline$S D$ & 5,487 & 5,212 & 4,79 & 2,454 & 5,463 & 2,625 \\
\hline
\end{tabular}

GFAP: glial fibrillary acidic protein; EB: ethidium bromide; Cur: curcumin

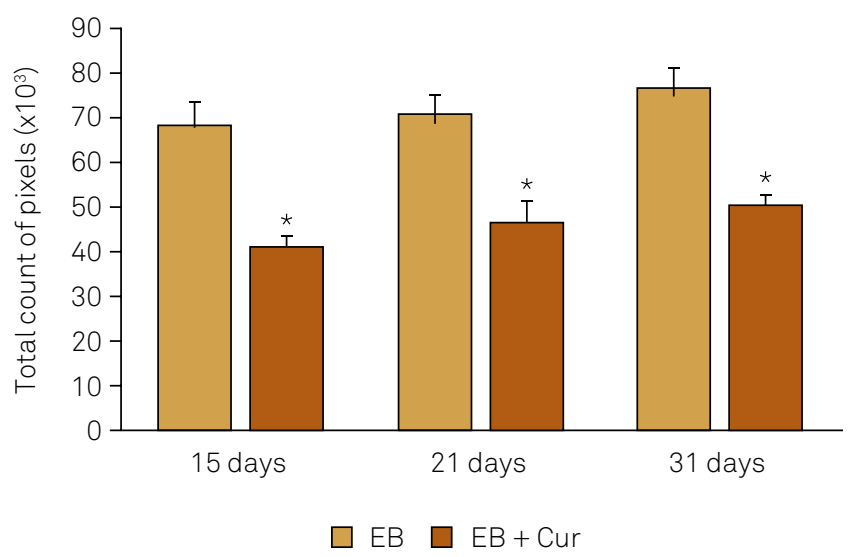

GFAP: glial fibrillary acidic protein; EB: ethidium bromide; Cur: curcumin Figure 3. GFAP expression at 15, 21 and 31 days in groups I (untreated rats) and II (rats treated with Cur) following EB injection. Data are shown as mean (total count of pixels) \pm standard deviation. $* p<0.05$.

Lymphocytes are invariably found in the EB demyelinating lesions, sometimes contacting myelin debris in the extracellular space and activated macrophages containing phagocytosed myelin, in a relationship suggestive of antigenic recognition. It is possible that macrophage and lymphocyte products during the inflammatory response triggered by EB injection may represent a more deleterious influence on nervous tissue than the previous gliotoxin injection itself. Therefore, the already described anti-inflammatory and immunomodulatory effects performed by $\mathrm{Cur}^{7,8,12}$ may possibly be beneficial to tissue repair.

Many distinct signaling molecules released by microglia, astrocytes, neurons, oligodendrocyte lineage cells, pericytes, endothelia and invasive inflammatory/immune cells, are able to trigger and regulate astrogliosis ${ }^{22,23}$. These molecular signals include: (a) large polypeptide growth factors and cytokines, such as IL-1, IL-6, TNF- $\alpha$, IFN- $\gamma$, TGF- $\beta$, LIF, CNTF, FGF2, among others; (b) mediators of innate immunity such as LPS and other Toll-like receptor ligands; (c) neurotransmitters such as glutamate and noradrenaline; (d) purines (e.g., ATP); (e) reactive oxygen species; (f) products associated with systemic metabolic activity (e.g., $\mathrm{NH}^{+}$) and (g) regulators of cell proliferation, such as endothelin $1^{22,23}$.

Cur has been shown to have bifunctional antioxidant properties, scavenging reactive oxygen species as well as simultaneously inducing an antioxidant response. Many other beneficial effects were reported for Cur, including the induction of cytoprotective enzymes, such as heme oxygenase-1, glutathione-S-transferase and $\gamma$-glutamyl cysteine ligase, the inhibition of caspase 1-dependent inflammation, the reversion of mitochondrial dysfunctions in astrocytes and the inhibition of mitochondria-dependent and -independent apoptosis caused by oxidative damage ${ }^{13}$.

As Cur is chemically quite unstable at $\mathrm{pH}>7$ and very poorly absorbed from the gastrointestinal tract, we chose the IP route for this study. According to uptake and bioavailability studies, the high proportion of fecal excretion after IP administration indicates good absorption from the peritoneal cavity and efficient elimination in the bile ${ }^{5}$. By comparison with an IP injected dose, the oral bioavailability of Cur is estimated at about only $1 \%^{5}$.

Lim et al. ${ }^{27}$ investigated whether Cur could affect Alzheimer's disease-like pathology in transgenic mice and noted that with low-dose Cur, but not with high-dose Cur, GFAP expression was decreased, and insoluble Abeta, soluble Abeta, and plaque burden were significantly reduced (by $43-50 \%$ ).

In our study, Cur treatment decreased the expected reaction of increased GFAP expression in astrocytes around EB-induced lesions at 15, 21 and 31 days compared to the untreated group. Inhibition of GFAP expression following CNS injury was also observed in several other investigations using Cur $^{9,13,15}$. Cur was able to reduce the expression of both GFAP mRNA and GFAP protein, as well as to induce autophagy and 
to rescue the filamentous organization of the GFAP mutant protein in an in vitro model of Alexander disease, in which heterozygous mutations of the GFAP gene are responsible for the intracytoplasmic accumulation of fibrous eosinophilic deposits known as Rosenthal fibers in dystrophic astrocytes ${ }^{28}$.

Morphometric analysis in the present investigation unequivocally demonstrated that Cur decreased astrocytic activation until the $31^{\text {st }}$ day after gliotoxic lesion, probably by suppressing the release of proinflammatory molecules, such as the previously-mentioned TNF- $\alpha$ and IL- $1 \beta$, which may trigger and promote astrogliosis following CNS injury. Thus, our results clearly indicate that this substance may be used in preventing or reducing glial scar development following injury.

Cur has been shown to regulate numerous transcription factors, cytokines, protein kinases, adhesion molecules, redox status and enzymes linked to inflammation ${ }^{6,7,8}$. As the inflammatory process plays a major role in most chronic illnesses, including neurodegenerative, cardiovascular, pulmonary, metabolic, autoimmune and neoplastic diseases, Cur undoubtedly presents a potential role in the prevention and treatment of various proinflammatory diseases ${ }^{8}$. These features, combined with the pharmacological safety, and negligible cost, render Cur an attractive agent to explore further.

\section{References}

1. Bondan EF, Lallo MA, Sinhorini IL, Pereira LA, Graça DL. The effect of cyclophosphamide on brainstem remyelination following local ethidium bromide injection in Wistar rats. J Submicrosc Cytol Pathol. 2000;32(4):603-12.

2. Graça DL, Bondan EF, Pereira LA, Fernandes CG, Maiorka PC. Behaviour of oligodendrocytes and Schwann cells in an experimental model of toxic demyelination of the central nervous system. Arq. Neuropsiquiatr. 2001;59(2B):358-61. https://doi.org/10.1590/S0004-282X2001000300009

3. Bondan EF, Lallo MA, Dagli MLZ, Sanchez M, Graça DL. [Investigation into the astrocytic immunoreactivity to GFAP and vimentin in the brainstem of Wistar rats submitted to the ethidium bromide gliotoxic model]. Arq Neuropsiquiatr. 2003;61(3A):642-9.Portuguese. https://doi.org/10.1590/S0004-282X2003000400022

4. Kuypers NJ, James KT, Enzmann GU, Magnuson DSK, Whittemore SR. Functional consequences of ethidium bromide demyelination of the mouse ventral spinal cord. Exp Neurol. 2013;247:615-22. https://doi.org/10.1016/j.expneurol.2013.02.014

5. Metzler M, Pfeiffer E, Schulz SI, Dempe JS, Curcumin uptake and metabolism. Biofactors. 2013;39(1):14-20. https://doi.org/10.1002/biof.1042

6. Hsu CH, Cheng AL. Clinical studies with curcumin. Adv Exp Med Biol. 2007;595:471-80. https://doi.org/10.1007/978-0-387-46401-5_21

7. Srivastava RM, Singh S, Dubey SK, Misra K, Khar A. Immunomodulatory and therapeutic activity of curcumin. Int. Immunopharmacol. 2011;11(3):331-41. https://doi.org/10.1016/j.intimp.2010.08.014

8. Aggarwal BB, Harikumar KB. Potential therapeutic effects of curcumin, the anti-inflammatory agent, against neurodegenerative, cardiovascular, pulmonary, metabolic, autoimmune and neoplastic diseases. Int J Biochem Cell Biol. 2009;41 (1 \0:40-59. https://doi.org/10.1016/j.biocel.2008.06.010

9. Lin MS, Lee YH, Chiu WT, Hung KS. Curcumin provides neuroprotection after spinal cord injury.J Surg Res. 2011;166(2):280-9. https://doi.org/10.1016/j.jss.2009.07.001

10. Jin W, Wang J, Zhu T, Yuan B, Ni H, Jiang J et al. Anti-inflammatory effects of curcumin in experimental spinal cord injury in rats. Inflamm Res. 2014;63(5):381-7. https://doi.org/10.1007/s00011-014-0710-z

11. Wang YF, Zu JN, Li J, Chen C, Xi CY, Yan JL. Curcumin promotes the spinal cord repair via inhibition of glial scar formation and inflammation. Neurosci Lett. 2014;560:51-6. https://doi.org/10.1016/j.neulet.2013.11.050

12. Seyedzadeh MH, Safari Z, Zare A, Gholizadeh Navashenaq J, Razavi SA, Kardar GA et al. Study of curcumin immunomodulatory effects on reactive astrocyte function. Int Immunopharmacol. 2014;22(1):230-5. https://doi.org/10.1016/j.intimp.2014.06.035
13. Daverey A, Agrawal SK. Curcumin alleviates oxidative stress and mitochondrial dysfunction in astrocytes. Neuroscience. 2016;333:92-103. https://doi.org/10.1016/j.neuroscience.2016.07.012

14. $\mathrm{Ni} \mathrm{H,} \mathrm{Jin} \mathrm{W,} \mathrm{Zhu} \mathrm{T,} \mathrm{Wang} \mathrm{J,} \mathrm{Yuan} \mathrm{B,} \mathrm{Jiang} J$ et al. Curcumin modulates TLR4/NF-kB inflammatory signaling pathway following traumatic spinal cord injury in rats. J Spinal Cord Med. 2015;38(2):199-206. https://doi.org/10.1179/2045772313Y.0000000179

15. Yuan J, Liu W, Zhu H, Chen Y, Zhang X, Li L et al. Curcumin inhibits glial scar formation by suppressing astrocyte-induced inflammation and fibrosis in vitro and in vivo. Brain Res. 2017;1655:90-103. https://doi.org/10.1016/j.brainres.2016.11.002

16. Pereira LA, Dertkigil MS, Graça DL, Cruz- Höfling MA. Dynamics of remyelination in the brain of adult rats after exposure to ethidium bromide.J. Submicrosc. Cytol Pathol. 1998;30(3):341-8.

17. Lee KM, MacLean AG. New advances on glial activation in health and disease. World J Virol. 2015;4(2):42-55. https://doi.org/10.5501/wjv.v4.i2.42

18. Brenner M. Role of GFAP in CNS injuries. Neurosci Lett. 2014;565:7-13. https://doi.org/10.1016/j.neulet.2014.01.055

19. Yang Z, Wang, KW. Glial fibrillary acidic protein: From intermediate filament assembly and gliosis to neurobiomarker. Trends Neurosc. 2015;38(6):364-74. https://doi.org/10.1016/j.tins.2015.04.003

20. Fitch MT, Silver J. Astrocytes are dynamic participants in central nervous system development and injury responses. In Jessen KR, Richardson WD. Glial cell development. Oxford: Oxford University Press; 2001. p. 263-77.

21. Pekny M, Pekna M. Astrocyte intermediate filaments in CNS pathologies and regeneration. J Pathol. 2004;204(4):428-37. https://doi.org/10.1002/path.1645

22. Sofroniew MV. Molecular dissection of reactive astrogliosis and glial scar formation. Trends Neurosci. 2009;32(12):638-47. https://doi.org/10.1016/j.tins.2009.08.002

23. Sofroniew MV, Vinters HV. Astrocytes: biology and pathology. Acta Neuropathol. 2010;119(1):7-35. https://doi.org/10.1007/s00401-009-0619-8

24. Cregg JM, DePaul MA, Filous AR, Lang BT, Tran A, Silver J. Functional regeneration beyond glial scar. Exp Neurol. 2014;253:197-207. https://doi.org/10.1016/j.expneurol.2013.12.024

25. Bondan EF. Propentofylline decreases the production of TNF-alpha and IL-1 beta in the rat brainstem after a gliotoxic injury induced by ethidium bromide. J. Neuroimmunol. 2014;275(1-2):139. http://dx.doi.org/10.1016/j.jneuroim.2014.08.373

26. Hayakawa T, Noda M, Yasuda K, Yorifuji H, Taniguchi S, Miwa I et al. Ethidium bromide-induced inhibition of mitochondrial gene transcription suppresses glucose-stimulated insulin release in the mouse pancreatic beta-cell line betaHC9. J Biol Chem. 1998;273(32):20300-7. https://doi.org/10.1074/jbc.273.32.20300 

spice curcumin reduces oxidative damage and amyloid pathology in an Alzheimer transgenic mouse. J Neurosci. 2001;21(21):8370-7.
28. Bachetti T, Di Zanni E, Balbi P, Ravazzolo R, Sechi G, Ceccherini. Beneficial effects of curcumin on GFAP filament organization and down-regulation of GFAP expression in an in vitro model of Alexander disease. Exp Cel Res. 2012;318(15):1844-54. https://doi.org/10.1016/j.yexcr.2012.06.008 